Željana Pancirov Cornelisse

Universiteit van Zagreb

https://doi.org/10.18485/bgd_nlistiek_30.2018.ch13

\title{
TERUGBLIK OP DE ZAGREBSE NEERLANDISTIEK - MOTIVATIE OM DE STUDIE NEDERLANDS AAN TE VANGEN
}

\begin{abstract}
The year 2008 was a very important year, not only because of the economic crisis that hit the world that year but also because in 2008 the Chair of Dutch Language and Cultural Studies in Zagreb was founded. This paper explores through three different research phases the changes that took place in the motivation of the students to enroll in Dutch Language and Cultural Studies from its founding till present day. The crisis and the economic changes in Croatia most definitely had their influences on studying Dutch. This conclusion is made based on the results of the researches and polls amongst students of Dutch Studies in Zagreb in the period between 2010 and 2017. Following questions are the basis of these researches and hence of this paper: What was the motivation to study Dutch and has this motivation changed over the years? Has the image of the Netherlands and Belgium and their respective inhabitants influenced the decision to study Dutch or has it been more a matter of love for the language? What were the expectations at the start of the study and how real were this expectations once graduated?
\end{abstract}

Keywords: Dutch, Dutch Language and Cultural Studies, Zagreb, motivation, retrospective

\section{Inleiding}

In 2018 viert de vakgroep Nederlandse taal- en cultuurkunde aan de Faculteit der Geestes- en Sociale Wetenschappen te Zagreb haar tienjarig bestaan. Dat is een goede reden om te analyseren wat de motivatie is van de Kroatische leerlingen om voor deze studie te kiezen en student neerlandistiek te worden om in de toekomst de positieve aspecten te benadrukken.

Sinds de eerste generatie studenten werden regelmatig door middel van enquêtes en vanuit verschillende perspectieven, hun motivatie en verwachtingen getest. Wat waren determinerende factoren voor de studenten om Nederlands te studeren? Was dat de taal zelf, de bekende stereotypen, de mening van de omgeving of nog iets anders? Wat vinden ze jaren later over hun keuze om de studie Nederlands te doen? 
Dit artikel begint met de voorstelling in grote lijnen van de werking van de studie zelf. Daarna wordt het onderzoek in drie fasen verdeeld. Die geven een overzicht van de motivatie van de respondenten, de studenten en alumni, tussen 2010 en 2017. Uiteindelijk wordt op basis van deze gegevens een conclusie getrokken.

\section{Studie Nederlandse taal- en cultuurkunde te Zagreb}

De vakgroep Nederlandse taal- en cultuurkunde aan de Faculteit der Geestes- en Sociale Wetenschappen te Zagreb bestaat sinds het studiejaar 2008-2009. Voor 2008 kon men ook Nederlands leren op de faculteit, maar alleen als keuzevak op het lectoraat. De studie Nederlands in Zagreb is een zogenaamde double majorstudie, wat betekent dat de studenten twee voltijdse studies tegelijkertijd doen. Naast het Nederlands kunnen ze voor geestes- of sociale wetenschappen kiezen. Vaak valt de keuze toch op een andere Germaanse taal, voornamelijk Duits, Zweeds en Engels. Het hoeft geen betoog dat afstuderen in twee verschillende richtingen de alumni grotere mogelijkheden op de arbeidsmarkt geeft. Er zijn verschillende motivaties waarom studenten bepaalde combinaties kiezen. Aan de ene kant is er het feit dat de talen verwant zijn en daarom denken de studenten dat ze makkelijker geleerd kunnen worden waardoor de studies makkelijker zullen zijn. Aan de andere kant geeft de verscheidenheid van kennis na het afstuderen meer mogelijkheden om een baan in één van de (talen)combinaties te kiezen (bijvoorbeeld alleen docent Engels zijn) of om beide talen te combineren (bijvoorbeeld met het vertalen).

De studie Nederlandse taal- en cultuurkunde is specifiek in Kroatië (maar niet in de internationale neerlandistiek) omdat er met een zogenaamde cyclische inschrijving gewerkt wordt. Dat wil zeggen dat er met slechts twee generaties studenten tegelijkertijd aan de slag wordt gegaan, maar ook met diegenen die hun scriptie nog af moeten ronden. In het begin van 2018 kunnen er vijftien afgestudeerden worden geteld. Nieuwe inschrijvingen vinden pas plaats als de oudere generatie de colleges heeft afgerond, zijnde na drie jaar. De volgende ronde van inschrijvingen zal in 2018 plaatsvinden voor het academische jaar 2018-2019. Tot nu toe heeft de studie Nederlands in Zagreb vier generaties studenten gehad. Daarbij moet worden opgemerkt dat de interesse voor de studie altijd groot was, zelfs op die momenten dat er geen inschrijvingen mogelijk waren. Haar tinnen jubileum gaat de vakgroep vieren met de inschrijving van twintig nieuwe studenten; de vijfde generatie. Toen de studie net was opgericht en de eerste generatie kon worden ingeschreven, waren er 240 kandidaten voor slechts zestien plaatsen. Sinds de toetreding van Kroatië tot de Europese Unie in 2013 is op te merken dat het aantal kandidaten flink is gestegen. Bij de laatste inschrijving in 2015 waren er zelfs 366 kandidaten. De eerste twee generaties hadden dertig ingeschreven studenten en de andere twee zestien studenten per studiejaar. De meeste studenten vinden het niet voldoende om alleen de bachelorstudie af te ronden. Daarom kiezen ze voor het volle traject (bachelor en master), hoewel veel van die studenten uiteindelijk helemaal niet zullen afstuderen. De oorzaak daarvoor 
ligt niet uitsluitend bij de opleiding neerlandistiek. De studenten moeten immers aan de voorwaarden voor hun beide double major studies voldoen om hun diploma te behalen. Als bijvoorbeeld de studenten alle tentamens bij de studie Nederlands succesvol hebben afgelegd maar bij hun andere studie niet, kunnen ze uiteindelijk bij geen van hun beide studies afstuderen.

Gezien de ontstaansgeschiedenis van de studie (en het aantal studenten dat per jaar de studie volgen) moet er rekening worden gehouden met een beperkt aantal respondenten voor de gemaakte onderzoeken gepresenteerd in dit artikel. Ondanks hun kleine aantal hebben de studenten en alumni toch hun best gedaan om uitgebreide antwoorden te geven.

In februari 2018 heeft de Faculteit der Geestes- en Sociale Wetenschappen te Zagreb een opendeurdag georganiseerd. Tijdens dit evenement konden alle afdelingen en vakgroepen binnen de faculteit hun programma's aan toekomstige studenten introduceren. Diegenen die de lezingen en workshops van neerlandistiek hebben gevolgd, waren in het algemeen wel bekend met Nederland (België kwam niet of nauwelijks aan bod) en het Nederlands, en wilden daar meer over weten. Tijdens de gesprekken met hen was te merken dat hun interesse in de studie vooral is ingegeven door de wens in Nederland te gaan wonen of omdat ze denken dat ze na het afstuderen met het Nederlands makkelijk een baan kunnen krijgen, omdat de concurrentie kleiner is. Pas in de herfst 2018 bij het afronden van de inschrijving van de vijfde generatie kan er gepeild worden naar de werkelijke motivatie van alle twintig nieuwe studenten; bovengenoemde is enkel wat de kandidaten hebben benadrukt. Toch dringt de vraag zich op of de motivatie van de toekomstige studenten anders zal zijn dan die van de studenten die nu Nederlands studeren of al afgestudeerd zijn. Zullen de resultaten die een onderzoek naar de motivatie van de nieuwe studenten een reflectie zijn van de resultaten van de andere onderzoeken die door de jaren heen werden gedaan?

\section{De invloeden op de motivatie om het Nederlands te studeren}

In de afgelopen tien jaar is er veel veranderd, vooral rond de gebeurtenissen die voor Kroatië en haar burgers belangrijk zijn. Denk aan de economische wereldcrisis (2008) die de interne problemen sinds de onafhankelijkheid (het laatste twintig jaar) alleen sterker heeft benadrukt (Benolić 2012) en de toetreding van Kroatië tot de Europese Unie (2013). Om betere kansen te hebben in het buitenland is kennis van vreemde talen een absolute must, wat talenstudies steeds populairder heeft gemaakt.

Sinds het begin van de economische wereldcrisis in 2008 is de werkloosheid in Kroatië geleidelijk aan gestegen. De resultaten zijn voornamelijk teleurstellend en ontmoedigend voor jongeren onder 25 jaar. In maart 2016 was het werkloosheidspercentage binnen deze leeftijdsgroep 11,4\% in Nederland, 20,3\% in België en $31,4 \%$ in Kroatië. De jeugdwerkloosheid is bijna het dubbele van de werkloosheid van de andere leeftijdsgroepen (Eurostat 2016). Benolić (2012) heeft een onderzoek bij 213 studenten rechten gedaan over hoe de wereldcrisis Kroatië heeft beïnvloed. Deze studenten zijn van mening dat de slechte situatie in het land 
voornamelijk door de binnenlandse politiek is veroorzaakt en dat de lokale politici de wereldwijde crisis de schuld geven in plaats van de hand in eigen boezem te steken. $45,8 \%$ van de studenten denkt dat ze moeilijk een baan zullen vinden en $80 \%$ zou graag in het buitenland willen werken. De redenen om naar het buitenland te verhuizen zijn hogere lonen en een betere levensstandaard. Omdat 9.6\% van de respondenten nooit terug zou komen indien ze een geschikte baan in het buitenland zouden krijgen, wordt in Kroatië een tendens van braindrainwaargenomen. ${ }^{1}$ Er wordt geschat dat tot het jaar 2019200.000 mensen (op een totale bevolking van ongeveer 4,3 miljoen) Kroatië gaan verlaten ("Croatian President Kolinda Grabar- Kitarovic from Peace, Recession to Feminism" 2015).

Verhuizen naar het buitenland is sinds 2013 met de toetreding van Kroatië tot de Europese Unie, makkelijker geworden. Dat kon eveneens bij de studenten Nederlands gemerkt worden. Vaak maakten ze tijdens de lessen de opmerking dat sinds de crisis alles in Kroatië slechter gaat en dat de enige oplossing is om naar het buitenland te verhuizen. Nederland noemden ze een promised land, hoewel de rest van de bevolking die dus geen Nederlands studeert, Duitsland en Oostenrijk aantrekkelijker vond (Velan 2013). Moesten de Nederlanders bang zijn voor al die Kroaten die naar Nederland wilden verhuizen? Rond het tijdstip van de toetreding van Kroatië verscheen in het Nederlandse Trouw (28-6-2013)een artikel met een opmerking over de Kroaten die mogelijk Europa gaan overspoelen:

De clichés over de Oost-Europeaan die de banen van westerlingen inpikt, kunnen weer uit de kast worden gehaald. [...] Want er komen niet alleen 'hoeren' maar ook andere werknemers (meest immigranten) die de 40 administratieve en organisatorische banen zullen bezetten, ter ondersteuning van de prostituees bij hun dagelijkse en nachtelijke activiteiten met hun klanten (Velan 2013).

In Nederland wonen rond tienduizend Kroaten en hun nakomelingen. De meesten zijn er tijdens de onafhankelijkheidsoorlog (in Kroatië de Vaderlandse oorlog genoemd) in de jaren negentig van de twintigste eeuw aangekomen ("Hrvatsko iseljeništvo u Nizozemskoj" 2018). In België wonen ongeveer zesduizend Kroaten en hun nakomelingen. De meesten zijn in Wallonië gevestigd ("Hrvatsko iseljeništvo u Belgiji i Luksemburgu" 2018). ${ }^{2}$ Volgens de cijfers kunnen Nederlanders en Belgen voorlopig rustig blijven. De wens om naar de Lage Landen bestaat wel, maar wordt niet zo snel tot werkelijkheid gebracht.

1 Benolić geeft een opmerking dat deze percentages eventueel zouden kunnen variëren als de respondenten uit een technische vakgebied zouden komen.

2 Als vergelijking wonen er in Duitsland meer dan 350000 Kroaten. 


\section{Methode}

Om de centrale vragen te kunnen beantwoorden en een analyse van de motivatie te kunnen geven, moet eveneens verwezen worden naar eerdere onderzoeken (2010 $\mathrm{t} / \mathrm{m}$ 2017) in verband met de vakgroep Nederlandse taal- en cultuurkunde te Zagreb en de motivatie van de studenten om voor deze studie te kiezen. Daarom worden de resultaten in drie fasen verdeeld. Alle gegevens zijn met behulp van enquêtes verkregen en verwerkt. Verder in de tekst wordt alleen de relevante informatie gegeven, hoewel sommige enquêtes veel uitgebreidere resultaten hadden.

De eerste fase houdt het onderzoek in dat schriftelijk plaatsvond in 2010. In dat onderzoek werd er gekeken naar hoeveel de eerste twee generaties studenten over het Nederlands taalgebied weten, wat hun motivatie was om de studie aan te vangen en wat ze voor de Kroatische gemeenschap kunnen betekenen. De resultaten zijn gepubliceerd in het artikel The Importance of Learning the Dutch Language and Culture for the Croatian Society (Pancirov Cornelisse 2011).

In de tweede fase werden de nieuwkomers (derde en vierde generatie) aan het begin van het eerste jaar schriftelijk getest naar hun basiskennis over Nederland en België en de algemene beeldvorming. De motivatie om neerlandistiek te studeren komt ook aan orde. Deze enquêtes zijn gedaan in het academisch jaar 2013-2014 en 2014-2015.

De derde fase bestaat uit twee delen - enquêtes uit 2015 en 2017 - waar precies dezelfde vragen werden gesteld over de motivatie om de studie Nederlands te doen en hoe hun omgeving naar die beslissing kijkt. De resultaten tonen hoe de motivatie over de jaren heen veranderde en wat eventueel de toekomst kan brengen voor de komende generaties.

De eerste fase

In de eerste fase werd het onderzoek bij de Kroatische studenten (toenmalige eersteen tweedejaars) in vier categorieën verdeeld: studeren bij de vakgroep; taal; toekomst; studie en studenten. De bedoeling was om te kijken wat de motivatie was om zich voor deze studie in te schrijven, wat de studenten van de studie zelf vinden, hoe ze hun toekomst met deze studie zien en hoe hun perceptie van de taal is, aangezien dat ze na één à twee jaar studie wat meer over de taal weten. Het onderzoek wijst uit dat de studenten het geweldig vinden om de eerste in iets te zijn. Dat creëert in hun ogen betere kansen voor de toekomst. Ze hebben voornamelijk voor het Nederlands gekozen omdat het goed combineert met hun andere studie (bijvoorbeeld Duits of Engels). Hun cultuurkennis gebruiken ze als een instrument om betere contacten met moedertaalsprekers en mogelijke handelspartners te maken. Ze zien hun toekomst voornamelijk als vertalers, docenten, in de diplomatie en in het toerisme. Hoe groter hun kennis van de Nederlandse taal en cultuur, hoe meer irritatie ze voelen wanneer iemand het Nederlands taalgebied in een verkeerde context gebruikt, bijvoorbeeld als iemand zegt dat Nederland tot de Scandinavische landen behoort. De studenten vonden aanvankelijk, net als hun omgeving, het Nederlands exotisch, maar toen ze eenmaal de taal begonnen te leren, veranderde hun perceptie volledig. Vanaf toen 
beschouwden ze als exotische talen die talen die in landen worden gesproken die geografisch veel verder van Kroatië liggen. Slechts één student zou Kroatië nooit verlaten. De anderen zouden het zonder te veel nadenken doen waarbij geld geen rol speelt. De studenten hebben voorzien dat de bloeitijd van hun vak in vijf à tien jaar plaats zal vinden (dus, tussen 2015 en 2020). Ze denken dat de toekomst, met hun kennis van het Nederlands, na de toetreding tot de Europese Unie, toegankelijker zal zijn (Pancirov Cornelisse 2011).

Dit onderzoek werd gedaan om een eerste beeld te krijgen van de motivatie van de studenten meteen na de oprichting van de vakgroep. De bedoeling was om op basis van de resultaten eventuele verbeteringen voor te stellen en te implementeren en zo de zwakkere punten te versterken. Uit de resultaten kan gezien worden dat het Nederlands aantrekkelijk is voor Kroatische studenten omdat de taal nog vrijwel onbekend is in de Kroatische gemeenschap. Daarbovenop wordt de cultuurkennis voordelig ingeschat in het kader van toekomstige contacten en eventuele plannen van de studenten om het land te verlaten.

De tweede fase

In de tweede fase van dit onderzoek werden de andere twee (jongere) generaties studenten getest. De enquêtes werden uitgedeeld aan het begin van hun studie, voor de eerste cultuurles. Tussen de eerste fase en de tweede fase van het onderzoek ligt drie en vier jaar en de vakgroep is ondertussen al vijf en zes jaar werkzaam. Het grotere publiek had de mogelijkheid om zich bekend te maken met wat de neerlandistiek inhoudt en wat de ervaringen van de andere (ex)studenten zijn. Sinds de oprichting van de vakgroep was het studieprogramma via internet toegankelijk.

De vragen van deze enquête zijn anders geformuleerd dan in de eerste fase, maar ze zijn eveneens georiënteerd op de motivatie van de studenten om de studie Nederlands te volgen. Ook wordt onderzocht hoe goed de studenten Nederland en België kennen en wat hun beeldvorming is van deze twee landen met het achterliggende idee om te onderzoeken of de beeldvorming (voornamelijk stereotypering) invloed had op de motivatie om neerlandistiek te studeren. Uit het academisch jaar 20132014 waren er zestien respondenten (zijnde alle ingeschreven studenten) en uit het academisch jaar 2014-2015 waren er tien.

De motivatie om Nederlands te leren is ongeacht de generatie voornamelijk op de taal gericht. De studenten vinden het Nederlands nieuw en interessant (exotisch wordt niet meer gebruikt als omschrijving)waardoor ze minder concurrentie op de arbeidsmarkt voorzien en dus makkelijker werk hopen te vinden. De taal zelf willen ze heel goed beheersen. 23\% van de studenten wil naar de Lage Landen verhuizen, hetzij om te studeren, hetzij om te werken of voor beide. Een andere belangrijke motivatie die de studenten aangeven om voor het Nederlands te kiezen is omdat het Nederlands tot de Germaanse talen behoort en daardoor goed met de studies Duits of Engels te combineren is. Studies Engels en Duits zijn populaire studies onder de Kroatische studenten. Negen van de ingeschreven eerstejaars Nederlands (in de derde en de vierde generatie studenten) heeft Duits als tweede double major studie. Voor het Engels als hun andere studie hebben vijf studenten gekozen. De andere combinaties 
zijn talen als Zweeds, Portugees of Frans, maar ook bijvoorbeeld kunstgeschiedenis, taalkunde, antropologie en informatiewetenschappen.

Over de cultuur (in de brede zin) leren vinden sommigen belangrijk, maar het is geen prioriteit. Als ze cultuur noemen, wordt dat voornamelijk in combinatie met de taal genoemd (Ik wil graag meer over de taal en cultuur leren). Afgezonderde reacties die genoemd kunnen worden als motivatie om met de studie te beginnen zijn: Ik heb voor neerlandistiek gekozen... Wegens de Nederlanders en hun levensstijl. Ik hoop dat ik daar ooit naartoe zal verhuizen. / Nederland is het land van de hoge levensstandaard. Hoeveel studenten over de Lage Landen weten voordat ze met de studie beginnen kan samengevat worden in de beweringen dat ze allemaal weinig of niet genoeg hier over kennen. 23\% van de respondenten denkt meer over Nederland dan over België te weten.

Er kan dus geconcludeerd worden dat in deze fase de taal toch een grotere rol heeft gespeeld dan de cultuur, waarmee de kennis van land en volk wordt bedoeld. De taal wordt nog steeds als nieuw beschouwd, wat het voor de studenten aantrekkelijk maakt. Bijna een kwart van de studenten wil in de toekomst naar de Lage Landen verhuizen, voornamelijk naar Nederland.

\section{De derde fase}

In de derde fase werden alle generaties studenten en alumni (verder in de tekst: de respondenten) twee keer met dezelfde vragen geënquêteerd. De eerste keer gebeurde dat in 2015. De tweede keer in 2017. Sinds het begin van de eerste fase is er veel veranderd op de vakgroep: de studie bestaat ondertussen al in totaal zeven en negen jaar. De kennis over wat de studie inhoudt en wat neerlandistiek überhaupt betekent (hoewel dat toch teleurstellend bleek te zijn) ${ }^{3}$ is in vergelijking met de eerdere fases alleen maar toegenomen, de eerste afgestudeerde studenten hebben hun eerste stappen op de arbeidsmarkt gewaagd, Kroatië is lid van de EU geworden en de braindrain is nog steeds een actueel onderwerp in het land.

\section{5}

De enquête uit 2015 is door 35 respondenten ingevuld; afgestudeerden $(\mathrm{N}=8)$, ouderejaars studenten $(\mathrm{N}=10)$ en eerste- en tweedejaars $(\mathrm{N}=17)$. De motieven om met de studie neerlandistiek te beginnen zijn: $i k$ wist niets over het Nederlands taalgebied (23\%), ik moest wel iets studeren (20\%), ik ben verliefd geworden op de taal (14\%), ik ben verliefd geworden op de cultuur van het Nederlands taalgebied (11\%). Eén respondent

3 In 2016 werd via een korte online enquête aan de Kroaten $(\mathrm{N}=100)$ gevraagd of ze weten wat nederlandistika betekent. De meeste respondenten waren tussen 25 en 54 jaar met tenminste een afgeronde masteropleiding. 49\% van de geënquêteerden heeft nooit van nederlandistika gehoord. Veertien respondenten zeiden dat het over de wetenschap over de Nederlandse taal en letterkunde gaat en twaalf respondenten zeiden over de Nederlandse taal en cultuur leren. Maar twee respondenten wisten dat nederlandistika met het Nederlands taalgebied verbonden is. De meest bizarre antwoorden waren: Heeft dat iets te maken met wiskunde of statistiek? en Het heeft te maken met Neanderthalers; in ieder geval met prehistorie. 
zei dat de stereotypes over Nederland de reden waren om deze studie te doen. Geen enkele respondent wilde deze studie volgen vanwege de stereotypes over België of Vlaanderen. De concrete vraag Hebben de stereotypen over Nederland uw beslissing beïnvloed om deze studie Nederlands te doen? toonde echter andere resultaten. Hoewel de meesten beantwoordden dat dit geen rol had gespeeld bij hun keuze (Voor deze studie wist ik weinig over de Nederlandse cultuur), waren zes antwoorden toch positief (Ja, ik wilde deze studie doen omdat Nederlanders tolerant zijn, zeker toleranter dan de Kroaten). ${ }^{4}$

Als ze in 2015 voor de eerste keer een keuze zouden moeten maken en opnieuw deze studie zouden kiezen, wat zou dan hun motivatie zijn? In dat geval zou de grootste motivator zijn om te gaan vertalen $(23 \%)$ en omdat de respondenten denken dat ze in het algemeen een goede toekomst met deze studie hebben (17\%). Ondanks de situatie in het land zelf waarbij veel hogeropgeleiden Kroatië verlaten om naar het buitenland te gaan, gaf maar $16 \%$ van de respondenten aan dat verhuizen naar het buitenland hun motivatie voor deze studie is. Van die $16 \%$ wil de helft in Nederland wonen en geen enkele in België. Als er specifiek gevraagd wordt of ze hun toekomst in Nederland of België zien, heeft 29\% misschien beantwoord, $26 \%$ nee en $23 \% \mathrm{ja}$. Drie respondenten vinden Nederland hun nieuwe mogelijke thuisland en twee studenten denken hetzelfde over België.

De respondenten zijn nog steeds van mening dat ze meer over Nederland dan België weten, maar hun eigen inschatting is dat ze nu België prima kennen, maar dat het altijd beter kan.

\section{7}

De enquête uit 2017 werd door 28 respondenten ingevuld; afgestudeerden $(\mathrm{N}=12)$, ouderejaars studenten $(\mathrm{N}=2)$ en derde- en vierdejaars (die in de enquête van 2015 de eerste- en tweedejaars waren) $(\mathrm{N}=14)$. De motieven om met de studie neerlandistiek te beginnen zijn: $i k$ wist niets over het Nederlands taalgebied (21\%), ik moest wel iets studeren (18\%), ik ben verliefd geworden op de taal (14\%), ik ben verliefd geworden op de cultuur van het Nederlands taalgebied (18\%). Twee respondenten hebben gezegd dat neerlandistiek studeren hun grote droom was. De bijzonderheid van de taal was slechts volgens één student de reden om deze studie te gaan doen. Stereotypen over Nederlanders en Belgen waren voor maar twee respondenten de reden waardoor ze in deze studie geïnteresseerd zijn geraakt. Op de vraag of de stereotypen toch wel invloed hadden op de keuze van de studie, hebben twee respondenten nader uitgelegd dat de vrije maatschappij en de tolerantie dicht bij hun eigen manier van denken staat en dat dat zeker aantrekkelijk was voor hen.

Als ze in 2017 voor de eerste keer voor deze studie zouden moeten kiezen, zou hun motivatie anders zijn? $32 \%$ heeft gezegd dat ze neerlandistiek in het algemeen zeer interessant vinden en daarom zou dat de keuze van hun toekomst zijn. 25\% zou voor deze studie kiezen om te kunnen vertalen. $11 \%$ denkt dat ze met neerlandistiek een

4 De Kroaten zijn traditioneler dan de Nederlanders omdat er in Kroatië $86.3 \%$ zelfverklaarde roomskatholieken wonen (Croatian Bureau of Statistics 2013, 14). 
goede toekomst in Kroatië hebben terwijl een andere 11\% juist het tegenovergestelde denkt. $11 \%$ ziet dus geen toekomst in neerlandistiek en zou deze keuze nooit meer maken. Bij het nader uitleggen van hun antwoorden blijkt dat de respondenten graag willen vertalen, maar ook lessen Nederlands willen geven. Met het vertalen denken ze het meest te kunnen verdienen. Men kan ook als freelancer werken als er geen vaste baan beschikbaar is. Hoewel sommige van onze studenten en alumni vertalen, is er nog geen enkele alumnus/a van onze studie die als beëdigd vertaler werkt, wat zeer opmerkelijk is. Deze vertalers zijn voornamelijk mensen die in de Lage Landen zijn geboren en getogen (of daar hebben gewoond) en studenten van het lectoraat waar de taalverwerving werd gegeven voordat de studie Nederlandse taal- en cultuurkunde werd opgericht. Uit cijfers van 2011 blijkt dat er toen 1206 beëdigd vertalers waren voor het Engels, 853 voor het Duits en 16 voor het Nederlands (Pancirov Cornelisse 2011, 310). In 2018 is het aantal van de beëdigd vertalers voor het Engels gestegen naar 1473, net als voor het Duits naar 958. Voor het Nederlands is dat aantal gedaald. Er zijn nu nog maar 12 beëdigd vertalers. Omdat zulke vertalers een extra examen over het rechterlijke systeem moeten afleggen en nog stage bij een andere beëdigd vertaler moeten lopen, is het niet vanzelfsprekend dat iemand met een diploma neerlandistiek dit werk meteen kan doen (“Sudačka mreža” 2018).

Op de concrete vraag Hebben de stereotypen over Nederland uw beslissing beïvloed om deze studie Nederlands te doen? hebben de respondenten veel andere antwoorden gegeven in vergelijking met twee jaar eerder. Het blijkt dat in 2017 minder studenten een instemmend antwoord op deze vraag hebben gegeven - enkel twee. Voor die twee respondenten speelde de tolerantie een grote rol.

$11 \%$ wil graag naar het buitenland verhuizen en $7 \%$ daarvan naar Nederland. Geen enkele respondent heeft aangegeven in België te willen wonen. In de antwoorden waar ze meer uitleg moesten geven, blijkt dat wonen in het buitenland aantrekkelijk is (hoewel iets minder aantrekkelijk dan in 2015) en dat het toch meer een droom is dan dat ze het realiteit zien worden. Toch zeiden enkele respondenten dat ze het leven in Kroatië wel prima vinden.

De respondenten hebben dezelfde mening over de kennis van Nederland en België als twee jaar eerder. Hun kennis van Nederland schatten ze hoger in dan hun kennis van België hoewel de kennis van beide landen altijd beter kan.

\section{De verschillen}

Hoewel er in 2017 minder respondenten waren, schijnt de motivatie om de studie Nederlands te doen voornamelijk te berusten op het toeval. De meerderheid van de respondenten wist voor de aanvang van hun studie niets over het Nederlandse taalgebied en omdat ze iets wilden studeren, bleek het Nederlands een willekeurige optie. Er is ook meer interesse voor neerlandistiek als geheel (dus de taal, de kennis van land en volk en de cultuur van het Nederlands taalgebied in het algemeen). De meeste respondenten denken dat ze met neerlandistiek een toekomst hebben. Als ze een specifiek carrièrepad moeten kiezen, zien de respondenten zich het liefst in de rol van vertaler. De stereotypen over land en volk spelen nauwelijks een rol in de keuze van de studie. Tussen de enquêtes van 2015 en 2017 is opmerkelijk dat in de meest 
recente er minder respondenten zijn die Kroatië willen verlaten en dus hun toekomst in eigen land willen opbouwen. Omdat het om ouderejaars en afgestudeerden gaat, is het een positief beeld dat steeds meer respondenten een betere toekomst in hun thuisland zien. Dat is natuurlijk ook voordelig voor de toekomst van de neerlandistiek in Kroatië.

\section{De omgeving en de toekomst}

De respondenten hebben hun mening gegeven over de keuze van de studie en wat ze uiteindelijk daarmee willen bereiken. Het blijkt dat ze weinig over het Nederlands taalgebied wisten voordat ze met de studie begonnen. In de enquêtes werd ook gevraagd over wat de omgeving van de respondenten over hun studiekeuze en neerlandistiek in het algemeen denkt. Zouden de mensen in de onmiddellijke omgeving van de studenten ook zo weinig kennis hebben over wat een studie neerlandistiek inhoudt? Uit de resultaten is af te lezen dat de meeste mensen verbaasd zijn over het feit dat een studie als neerlandistiek überhaupt bestaat. Men heeft geen enkel idee wat iemand met een dergelijk studie of beroep kan bereiken en doen. Vaak vraagt men of de studenten hen iets in het Nederlands kunnen zeggen en of ze hun iets meer over de taal zelf kunnen vertellen. Weinig mensen uit de omgeving van de studenten willen meer te weten komen over de studie in het algemeen. De taal zelf staat centraal. Enkelen willen horen of bepaalde stereotypen die ze kennen (voornamelijk over Nederland) correct zijn. In 2015 vroeg men de respondenten of ze van plan zijn om naar de Lage Landen te verhuizen. In 2017 gaf geen enkele respondent aan dat ze deze vraag vanuit hun naaste omgeving hebben gekregen.

De gegevens, die bekend zijn over alumni, laten zien dat de afgestudeerde neerlandici, afhankelijk van hun eigen motivatie, overal werk kunnen vinden. Als ze tijdens de studie al verschillende taken in de branche doen, kunnen ze nadien meteen en zonder problemen een vaste baan vinden. De meeste alumni hebben daarom al tijdens hun studiejaren als vertalers gewerkt (voornamelijk in de media), maar er zijn enkele die ook hele boeken hebben vertaald. Eén alumnus/a werkt als vertaler voor Europese Commissie. Een aantal studenten heeft hun toekomst in toerisme gevonden. De andere alumni die ook na hun studie met Nederlands werken, hebben een baan in een Nederlandstalig bedrijf. Niet alleen met een afgeronde master- maar ook met een bachelorstudie blijken er kansen op werk te zijn. Er zijn alumni die in de vrije tijd Nederlandse lessen geven aan de geïnteresseerden. Wegens de steeds toenemende migratie is de vraag naar deze lessen steeds groter. Eén alumnus werkte als stagiair voor de diplomatieke vertegenwoordiger in Kroatië en deze alumnus heeft later ook een baan gekregen als promovendus op de vakgroep waar hij als student van de eerste generatie begon. Er zijn alumni die hun toekomst in hun andere studievak hebben gevonden en uiteindelijk het Nederlands helemaal niet in professionele context gebruiken. 


\section{Conclusie}

De vakgroep Nederlandse taal- en cultuur te Zagreb viert in 2018 haar tienjarig bestaan. Dat is een goede kans om terug te blikken op de motivatie van de studenten om deze studie te doen zodat tijdens de promotie van de studie bij toekomstige generaties de sterke kanten benadrukt kunnen worden en dat er aan de minder sterke kanten gewerkt kan worden. Het onderzoek gebeurde op basis van verschillende enquêtes die over de jaren heen (van $2010 \mathrm{t} / \mathrm{m}$ 2017) peilden of de motivatie om neerlandistiek te studeren, is veranderd. Het overzicht werd in drie fases verdeeld. Samenvattend kunnen we concluderen dat hoewel de studenten aan het begin van de studie weinig over het taalgebied wisten, ze wel geïnteresseerd waren in de taal zelf. De eerste twee generaties vonden het Nederlands exotisch, terwijl de andere twee generaties de taal als nieuw en interessant omschreven. Voor iedereen was het een pluspunt dat met deze studie de studenten en alumni niet zo'n grote concurrentie hebben op de arbeidsmarkt wat in de toekomst voordelig kan zijn. Een andere voordeel van de studie, die een double major systeem heeft, is dat studenten een andere voltijdsstudie naast het Nederlands kiezen en daarmee een nog grotere kans op de arbeidsmarkt hebben. De studenten combineren neerlandistiek het liefst met een andere Germaanse taal omdat ze het makkelijker vinden om verwante talen samen te studeren. De meesten willen graag vertalen, wat, als we het patroon van de alumni onder de loep nemen, ze uiteindelijk ook wel doen. De markt voor de beëdigd vertalers is nog onontgonnen door de studenten. De wens om naar het buitenland te verhuizen bestaat, maar is verkleind over de jaren heen. Dat is opvallend aangezien het tegen de maatschappelijke trend ingaat die laat zien dat steeds meer Kroaten het land verlaten. Dat kan zeer voordelig zijn, niet alleen voor de alumni, maar ook voor de toekomst van de studie en onze toekomstige studenten.

\section{Literatuuropgave}

Benolić, Martina. 2012. "Svjetska ekonomska kriza: razvoj, utjecaj na Republiku Hrvatsku i subjektivni stavovi studenata". Pravnik: časopis za pravna i društvena pitanja 46 (92): 119-38.

Pancirov Cornelisse, Željana. 2011. "The Importance of Learning the Dutch Language and Culture for the Croatian Society". In Concepts and Consequences of Multilingualism in Europe 2. Tetovë: South East European University. 299-311.

\section{Internetbronnen}

Croatian Bureau of Statistics. 2013. "Census of Population, Households and Dwellings 2011, Population by Citizenship, Ethnicity, Religion and Mother Tongue." Statistical Reports 1333-1876. Zagreb. Geraadpleegd op 20 februari 2018 van 
http://www.dzs.hr/Hrv_Eng/publication/2012/SI-1469.pdf.

"Croatian President Kolinda Grabar- Kitarovic from Peace, Recession to Feminism". 29 juni 2015. Euronews. Geraadpleegd op 20 februari 2018 van http://www. euronews.com/2015/06/29/croatian-president-kolinda-grabar-kitarovic-frompeace-recession-to-feminism.

Eurostat. 2016. "Unemployment statistics". Eurostat. 2016. Geraadpleegd op 20 februari 2018 van http://ec.europa.eu/eurostat/statistics-explained/index.php/ Unemployment_statistics\#Youth_unemployment_trends.

"Hrvatsko iseljeništvo u Belgiji i Luksemburgu". 2018. Geraadpleegd op 20 februari 2018 van http://www.hrvatiizvanrh.hr/hr/hmiu/hrvatsko-iseljenistvo-u-belgiji-iluksemburgu/19.

"Hrvatsko iseljeništvo u Nizozemskoj". 2018. Geraadpleegd op 20 februari 2018 van http://www.hrvatiizvanrh.hr/hr/hmiu/hrvatsko-iseljenistvo-u-nizozemskoj/29.

"Sudačka mreža”. 2018. Geraadpleegd op 20 februari 2018 van http://www.sudackamreza.hr.

Velan, Elio. 2013. "De angst voor de Kroatische invasie". Trouw, 28 juni 2013, sec. Dossier. Presseurop. Geraadpleegd op 20 februari 2018 van http://www.trouw. nl/tr/nl/7504/Presseurop/article/detail/3466167/2013/06/28/De-angst-voor-deKroatische-invasie.dhtml. 